\title{
Reply to the Letter to the Editor: Surgery, selection, or biology in lung metastasectomy for colorectal lung metastasectomy? PulMiCC may not provide all the answers but it does narrow down the question
}

\author{
Stefan Sponholz ${ }^{1}$ (D) Joachim Schirren ${ }^{1}$ \\ Accepted: 19 September 2021 / Published online: 23 September 2021 \\ (c) The Author(s), under exclusive licence to Springer-Verlag GmbH Germany, part of Springer Nature 2021
}

\section{Dear Editor:}

We just read the Letter to the Editor of Tom Treasure and Misal Milosevic to our manuscript entitled "The impact of primary tumor location on prognosis after colorectal lung metastasectomy" published in your Journal in August this year.

On the one hand, we are very honored and thankful that Tom Treasure and Misal Milosevic congratulated us for our data, because they are two authors who really keep analyzing the impact of pulmonary metastasectomy in patients with colorectal cancer [1].

On the other hand, we want to clarify the statement that it is unfair that we mentioned that the PulMiCC trial was stopped due to poor recruitment [2]. It was not our intention to be unfair; we just cited the conclusions of the PulMiCC trial:

"Because of poor and worsening recruitment, the study was stopped" [3].

In total, we are looking forward for new results in the field of pulmonary metastasectomy in patients with colorectal cancer.

Best regards,

Stefan Sponholz and Joachim Schirren.

\section{References}

1. Treasure T, Milosevic M (2021) Surgery, selection or biology in lung metastasectomy for colorectal lung metastasectomy? PulMiCC may not provide all the answers but it does narrow down the question. Int J Colorectal Dis. 36(10):2281. https://doi.org/10. 1007/s00384-021-03916-8. Epub 2021 Mar 29. PMID: 33782765

2. Sponholz S, Oguzhan S, Mese M, Schirren M, Kirschbaum A, Schirren J (2021) The impact of primary tumor location on prognosis after colorectal lung metastasectomy. Int J Colorectal Dis 36(8):1731-1737. https://doi.org/10.1007/s00384-021-03907-9 (Epub 2021 Mar 12)

3. Treasure T, Farewell V, Macbeth F, Monson K, Williams NR, Brew-Graves C, Lees B, Grigg O, Fallowfield L (2019) PulMiCC Trial Group. Pulmonary Metastasectomy versus Continued Active Monitoring in Colorectal Cancer (PulMiCC): a multicentre randomised clinical trial. Trials. Dec 12;20(1):718. https:// doi.org/10.1186/s13063-019-3837-y. PMID: 31831062; PMCID: PMC6909580

Publisher's Note Springer Nature remains neutral with regard to jurisdictional claims in published maps and institutional affiliations.
Stefan Sponholz

Stefan.sponholz@fdk.info

1 Department of Thoracic Surgery, Agaplesion Markus Krankenhaus Frankfurt, Wilhelm-Epstein-Str. 4, 60431 Frankfurt, Germany 